\title{
Left ventricular aneurysms associated with intraoperative venting of the cardiac apex in children
}

\begin{abstract}
Left ventricular (LV) apical aneurysms were observed in 16 of $50(32 \%)$ children (average age 8 years) consecutively catheterized after surgical repair of congenital heart disease. The LV apex was vented by a sump during cardiopulmonary bypass in each. The aneurysms varied in size, but were generally small. Average dimensions were $7.5 \times 6.8 \mathrm{~mm}$ in the anteroposterior projection and $8.9 \times 5.7 \mathrm{~mm}$ in the left anterior oblique projection. The LV apex wall was thinner in patients with aneurysms than in ageand lesion-matched controls. All of the LV aneurysm patients were asymptomatic during average follow-up of 4 years . Nevertheless, such aneurysms are anticipated to represent a potential source of cardiovascular compllcations and, when possible, alternate methods for venting the left ventrlcle are recommended. (AM HEART J 101:622, 1981.)
\end{abstract}

Kenneth M. Weesner, M.D., Craig Byrum, M.D., and Amnon Rosenthal, M.D. Ann Arbor, Mich.

In some institutions, including our own, a sump is placed in the apex of the left ventricle (LV) to vent the chamber during open heart surgery. To determine if the procedure results in any subsequent structural or functional LV abnormality, we reviewed the clinical, hemodynamic and LV cineangiographic findings in 50 consecutive postoperative patients with congenital heart disease. This report describes the incidence, size, and clinical correlates of the observed LV apical aneurysms.

\section{METHODS}

Patients. The cineangiograms of all patients catheterized at our institution for postoperative evaluation between July 1, 1978, and June 30, 1979, were reviewed. The medical records including operative report and cardiac catheterization data of all patients with an LV apex abnormality were then obtained and examined. All the surgical procedures were performed utilizing cardiopulmonary bypass with $L V$ venting done through the $L V$ apex. The metalic sump used for venting varied in size from $10 \mathrm{~mm}$ to $12 \mathrm{~mm}$. The apical hole was closed with a purse-string suture of Tevdek and the repair usually reinforced by pledgets or deep mattress sutures.

Aneurysm characterization. Dimensions of the LV

From the Section of Pedialric Cadiology, Department of Pediatrics and the Section of Thoracic Surgery, Department of Surgery, University of Michigan Medical Center, C.S. Mott Chíldren's Hospital.

Received for publication Aug. 14, 1980; accepted Jan. 18, 1981

Reprint requests: Amnon Rosenthal, M.D. Pediatric Cardiology Section, F1115, C. S. Mott Children's Ilospital, University of Michigan Medical Center, 1405 E. Ann St., Ann Arbor, MI 48109. apical aneurysms were measured from the anterior-posterior (AP) and lateral, or left anterior oblique (LAO), projections of the $\mathrm{LV}$ cineangiogram using a magnification grid obtained at the time of cardiac catheterization. The largest dimension (L-axis) and the dimension at a perpendicular axis to the $\mathrm{L}$-axis were recorded. $\mathrm{LV}$ apical wall thickness was measured at the thinnest portion of the aneurysm using the same grids. For comparison, apical wall thickness was measured in a similar manner in 26 age-and cardiac lesion-matched controls. Statistical analysis was performed by group $t$ statistic.

\section{RESULTS}

Incidence. LV apical aneurysms were observed in 16 of $50(32 \%)$ patients in whom a sump had previously been placed in the LV apex during surgical repair. Mean age at repair of the cardiac lesion was 3.8 years (range 7 months to 9 years) and interval between operation and postoperative cardiac catheterization was 3.7 years (range 9 months to 12.5 ycars). Cardiac diagnoses in the 16 patients with apical aneurysm included ventricular septal defect (six), tetralogy of Fallot (five), aortic stenosis (two), and miscellaneous (three). No aneurysms or diverticula were noted in any of the patients on preoperative LV cineangiograms. Among the 34 patients without $\mathrm{LV}$ apex aneurysm, mean age at repair was 3.6 years (range 3 days to 6.9 years) and follow-up period was 5.6 years (range 1 to 16 years). Distribution of cardiac diagnosis was similar to the group with LV apex aneurysms.

Configuration. The aneurysms varied in shape from 


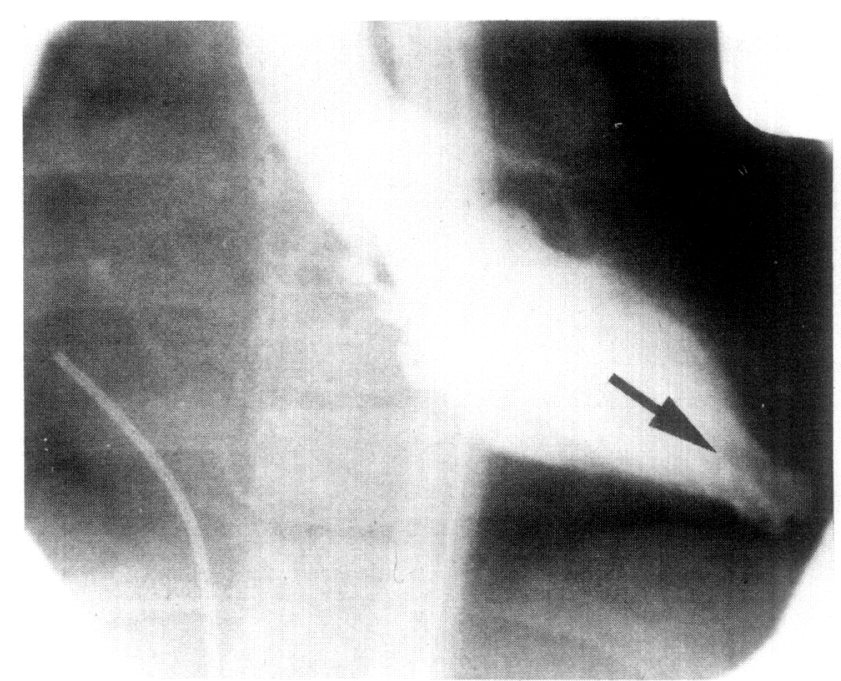

Fig. 1. LV apex sump aneurysm (arrow) during systole in an 11-year-old $b c y, 3$ years after surgical repair of a ventricular septal defect.

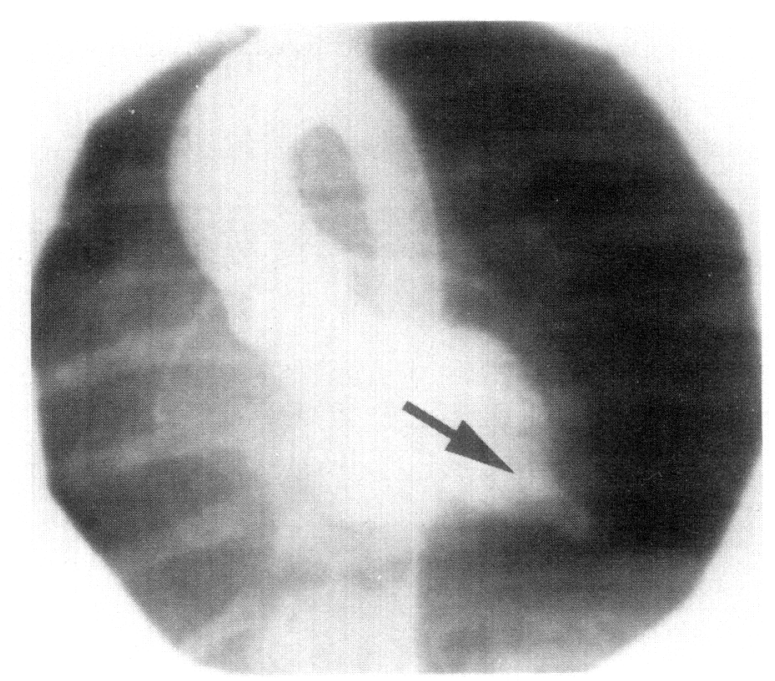

Fig. 2. LV cineangiogram during systole in a 4-year-old child, $2 \frac{1}{2}$ years after repair of tetralogy of Fallot. The LV sump aneurysm (arrow) measured $6.3 \times 6.0 \mathrm{~mm}$.

Table I. Morphology of LV apical sump aneurysms

\begin{tabular}{|c|c|c|c|c|}
\hline $\begin{array}{l}\text { Age at } \\
\text { surgery } \\
(y r)\end{array}$ & $\begin{array}{c}\text { Age at } \\
\text { PO cath } \\
(y r)\end{array}$ & $\begin{array}{c}\text { LVAS } \\
\text { dimensions* } \\
(\mathrm{mm})\end{array}$ & $\begin{array}{c}L V P \\
S / E D \\
(\mathrm{~mm} \mathrm{Hg})\end{array}$ & $\begin{array}{c}\text { LVAS wall } \\
\text { thickness } \\
(\mathrm{mm})\end{array}$ \\
\hline 0.6 & 2.3 & $6.4 \times 5.9 / 6.5 \times 6.2$ & $115 / 8$ & 5.6 \\
\hline 1.2 & 7.5 & $7.0 \times 7.0 / 10.8 \times 7.4$ & $108 / 9$ & 5.2 \\
\hline 1.5 & 2,5 & $3.5 \times 2.2 /-$ & $99 / 6$ & 3.8 \\
\hline 1.8 & 3.1 & $6.4 \times 6.0 / 7.6 \times 5.0$ & $101 / 10$ & 5.0 \\
\hline 2.0 & 3.5 & $6.9 \times 9.3 / 11.1 \times 6.2$ & $106 / 17$ & 1.3 \\
\hline 2.3 & 3.3 & $4.6 \times 5.4 / 6.4 \times 4.0$ & $127 /-$ & 4.0 \\
\hline 3.0 & 10.0 & $12.2 \times 7.8 / 10.0 \times 5.0$ & $110 / 15$ & 3.5 \\
\hline 4.0 & 5.0 & $6.4 \times 6.0 /-$ & $110 / 8$ & 4.4 \\
\hline 4.0 & 6.0 & - & $147 / 14$ & - \\
\hline 4.0 & 6.5 & $8.7 \times 3.0 / 12.4 \times 4.8$ & $120 / 10$ & 2.0 \\
\hline 5.0 & 15.0 & - & $100 /-$ & - \\
\hline 5.5 & 17.0 & $9.9 \times 7.8 / 10.0 \times 3.0$ & $110 / 5$ & 5.8 \\
\hline 7.5 & 11.0 & $7.8 \times 10.0 / 7.5 \times 9.3$ & $111 / 11$ & 3.0 \\
\hline 9.0 & 10.0 & $-/ 8.0 \times 5.2$ & $120 / 7$ & 2.5 \\
\hline 12.0 & 12.0 & $9.2 \times 10.8 /-$ & $150 / 20$ & 4.8 \\
\hline
\end{tabular}

LVAS = left ventricular apical sump aneurysm during systole; $\mathrm{LVP}=$ left ventricular pressures; $\mathrm{S}=$ peak systole; $\mathrm{ED}=$ end-diastole; $\mathrm{PO}$ cath $=$ postoperative catheterization.

*AP dimensions/lateral dimensions during systole.

round to oblong fingerlike projections (Figs. 1 to 3 ). Paradoxical motion during systole was observed in each. Adequate measurements of dimensions and wall thickness of the aneurysm. were possible in 14 of 16 patients (Table I). Average size of the aneurysm in the AP, projection was $7.5 \times 6.8 \mathrm{~mm}$ (range $3.5 \times 2.2$ to $12.2 \times 7.8 \mathrm{~mm}$ ) and in the lateral or LAO projection it was $8.9 \times 5.7 \mathrm{~mm}$ (range $6.4 \times 6$ to $12.4 \times 4.8 \mathrm{~mm}$ ). The thinnest portion of the $\mathrm{LV}$ wall at the aneurysm averaged $3.9 \mathrm{~mm}$ (range 1.3 to
$5.8 \mathrm{~mm}$ ). In contrast, the thinnest portion of the LV apex in age-and cardiac lesion-matched controls (Table II) was $9.2 \mathrm{~mm}$ (range 4.1 to $23.9 \mathrm{~mm}$ ) $(p<0.0002)$.

LV pressures. At postoperative cardiac catheterization in the 16 patients with $\mathrm{LV}$ apical aneurysm (Table I), LV peak systolic pressure averaged 116 $\mathrm{mm} \mathrm{Hg}$ (range 99 to $150 \mathrm{~mm} \mathrm{Hg}$ ) and simultaneous $\mathrm{LV}$ end-diastolic pressure averaged $11 \mathrm{~mm} \mathrm{Hg}$ (range 5 to $20 \mathrm{~mm} \mathrm{Hg}$ ). In the control group (Table 


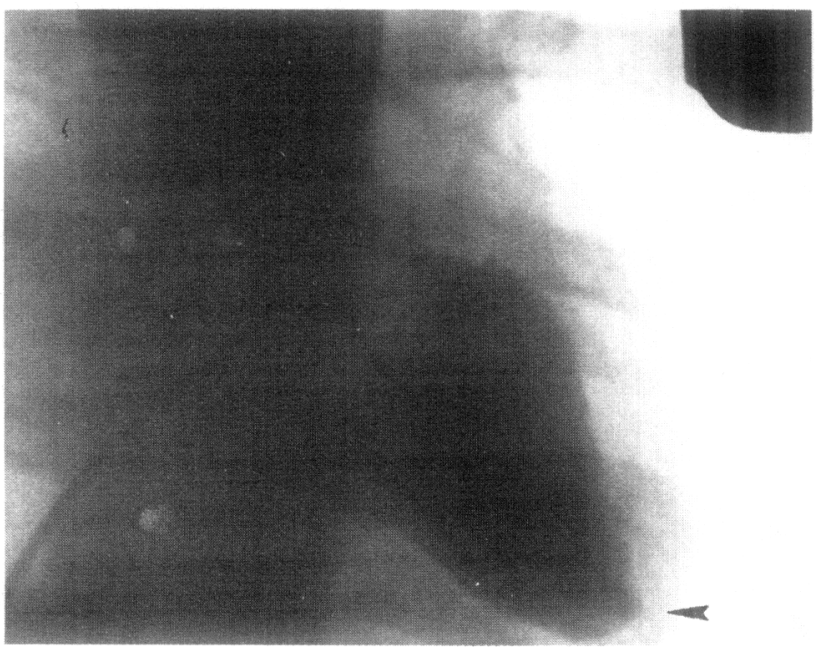

Fig. 3A. Selective $L V$ cineangiogram in a 17 -year-old boy, 5 years after aortic valvulotomy. Note absence of aneurysm at the $\mathrm{LV}$ apex at end-diastole (arrow).

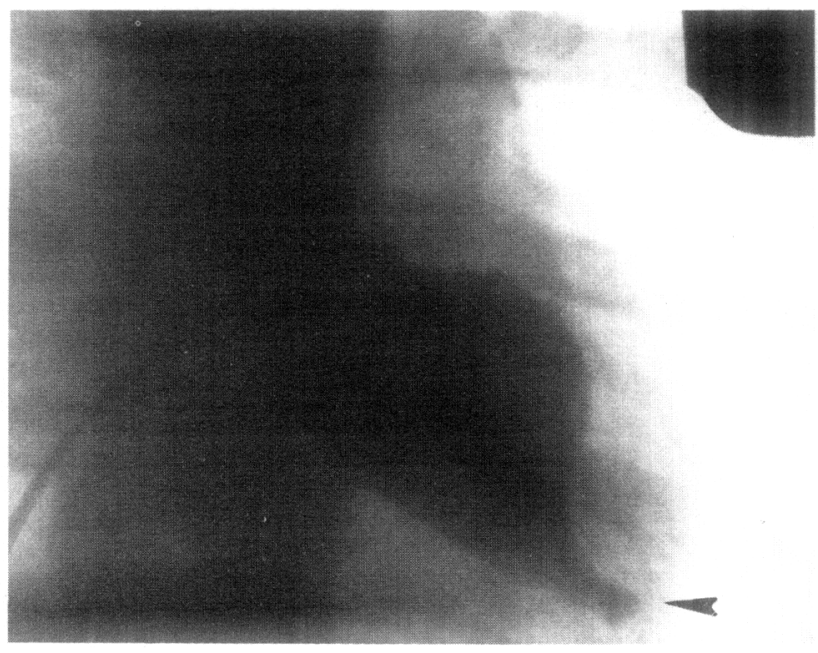

Fig. 3B. LV cineangiogram during systole in the same patient as in Fig. 3A, demonstrating a small sump aneurysm at the apex of the LV (arrow).

II), LV peak systolic pressure was $108 \mathrm{~mm} \mathrm{Hg}$ (range 90 to $255 \mathrm{~mm} \mathrm{Hg}$ ) and $\mathrm{LV}$ end-diastolic pressure was $10 \mathrm{~mm} \mathrm{Hg}$ (range 5 to $18 \mathrm{~mm} \mathrm{Hg}$ ).

Clinical observations. None of the patients had any signs or symptoms related to the aneurysm. No ventricular ectopic beats or myocardial infarction pattern were present on standard electrocardiograms. There were no rhythm disturbances on 24hour ECG recordings in the six patients in whom the test was performed. M-mode echocardiography was unable to identify or delineate the aneurysms.

\section{DISCUSSION}

Causes of LV aneurysms. LV aneurysms may be congenital in origin, ${ }^{1-3}$ or may occur as a conse-
Table II. LV apical wall thickness during systole in matched controls

\begin{tabular}{cccc}
\hline $\begin{array}{c}\text { Age group } \\
\text { (yr) }\end{array}$ & $\begin{array}{c}\text { Patients } \\
\text { (no.) }\end{array}$ & $\begin{array}{c}\text { Range } \\
(\mathrm{mm})\end{array}$ & $\begin{array}{c}\text { Mean } \\
(\mathrm{mm})\end{array}$ \\
\hline $1-2$ & 5 & $4.8-7.4$ & 6.3 \\
$3-4$ & 6 & $4.1-11.8$ & 7.7 \\
$5-8$ & 6 & $7.9-14.8$ & 10.8 \\
$9-13$ & 5 & $6.9-23.9$ & 11.5 \\
$13-18$ & 4 & $8.8-15.2$ & 10.8 \\
\hline
\end{tabular}

quence of myocardial infarction, ${ }^{4}$ penetrating chest trauma, ${ }^{7}$ or an infectious process. ${ }^{2} L V$ aneurysms as a complication of open heart surgery have been reported after mitral valvulotomy, mitral valve replacement, and myotomy performed for relief of idiopathic subaortic stenosis., ${ }^{2,}{ }^{5}$ Large false aneurysms resulting in symptoms have been described following venting of the $L V$ in children with congenital heart disease. ${ }^{5}$ However, to our knowledge, there have been no studies on the frequency and characteristics of LV true aneurysms produced by venting the $L V$ with a sump.

Morphology and related features. Our study indicates that $32 \%$ of patients in whom an LV sump is used may be expected to develop an aneurysm. The aneurysm is generally small and its size seems to be independent of the type of cardiac lesion, LV pressure, age at initial surgery, or duration of follow-up. The wall of the aneurysm appears to be considerably thinner than the LV apex in matched controls. During systole there is paradoxical motion of the $L V$ apex.

Potential complications. Follow-up of our patients shows no adverse effects from the LV apical aneurysms. However, potential complications which may develop with advancing age are arrhythmias, rupture, thromboembolism, and endocarditis. Progressive enlargement later in life might be anticipated in instances of occurrence of an additional disorder, such as ischemic heart disease. These potential complications are similar to those reported with $L V$ aneurysms from other causes.., 4, 7,8 Several reports have described the surgical removal of an LV apex pseudoaneurysm in patients who became symptomatic., 5. 9

Pathogenesis. LV sump aneurysms may occur as a result of focal infarction between interlocking sutures or tearing of lightly placed stitches. ${ }^{6.9 .10}$ Localized weakness or scar of the LV apex at the myotomy site may gradually enlarge and thin out. Although we have no pathologic studies of the aneurysms, the morphology on cineangiogram and 
clinical course of the patients suggest that the aneurysms observed are true rather than false or pseudoaneurysms. Whereas $\mathrm{LV}$ false aneurysms may be rapidly progressive, result in symptoms, and require reoperation, these true sump aneurysms are usually small and incidental at postoperative cardiac catheterization. It is anticipated that recognition may be facilitated with two-dimensional echocardiography and or Doppler technique. ${ }^{9}$ In postoperative patients with ectopy and a sump aneurysm, electrophysiologic studies may be useful in determining if the aneurysm is the source of such ectopy.

Conclusions. Since the incidence of LV sump aneurysms appears to be relatively high following the use of LV sumps, it would seem advisable to use an alternate melhod of venting the $L V$ when possible. The left atrium or pulmonary veins may be vented directly if venting is deemed necessary. While no serious complications of true LV sump aneurysms have been reported to date, these aneurysms are a potential source for cardiovascular complications with advancing age.

\section{REFERENCES}

1. Wennevold A, Anderson ED, Efsen F, Jacobsen JR, Lauridsen P: Congenital apical aneurysm of the left ventricle: Surgical removal in two infants. Eur J Cardiol 7:411, 1978.

2. Robinson MB, Donahoo JS: Post-operative aneurysms of the heart: Case report and review of the literature. I Cardiovase Surg 18:181, 1977.

3. Treistman B, Cooley D, Lufochamowski $R$, Leachman R: Diverticulum or aneurysm of left ventricle. Am J Cardiol 32:119, 1973.

4. Favaloro RG, Effler DB, Groves LK, Westcott RN, Suarey $\mathrm{F}$, Logada J: Ventricular aneurysms: Clinical experience. Ann Thorac Surg 6:227, 1968.

5. Lee SJ, Ko PT, Hendin ID, Sterns LP: False left ventricular aneurysm as a complication of open heart surgery. Can Med Assoc J 115:45, 1976.

6. Spellberg RD, O'Reilly RJ: Pseudoaneurysm of the left ventricle after mitral valve replacement. Chest 62:115, 1972.

7. Lyons C, Perlious RJ: Resection of LV aneurysm $2^{\circ}$ to cardiac stab wound. Ann Surg 147:256, 1958.

8. Jauz RF, Waldrou RJ: Predicted effect of chronic apical aneurysms on the passive stiffness of the human left ventricle. Circ Res 42:255, 1978.

9. Fallah-Nejod M, Abelson DM, Blakemore WS: Left ventricular pseudoaneurysm. A rare complication of open heart surgery with unusual Doppler manifestations. Chest 61:00, 1972.

10. Harley MRS: Cardiac ventricular aneurysms. Thorax 24:148, 1969. 